\title{
AVALIAÇÃO DE TREINAMENTO PROFISSIONAL PARA TRABALHADORES DO CONHECIMENTO: um estudo de caso em uma instituição pública de educação, ciência e tecnologia do Nordeste do Brasil
}

\author{
A. B. C. CASTRO ${ }^{1}{ }^{*}$; R. M. A. OLIVEIRA ${ }^{1}$; E. C. SOARES NETO ${ }^{1}$; M. A. OLIVEIRA ${ }^{1}$; P. M. M. SILVA ${ }^{2}$ e A. W. P. SILVA ${ }^{2}$ \\ ${ }^{1}$ Instituto Federal de Educação, Ciência e Tecnologia do Rio Grande do Norte \\ ${ }^{2}$ Universidade Potiguar \\ brunnicastro@hotmail.com*
}

Submetido 07/10/2016 - Aceito 13/06/2018

DOI: $10.15628 /$ holos.2018.5170

\section{RESUMO}

O objetivo desta pesquisa foi avaliar o suporte organizacional para aprendizagem e o impacto do Curso de Aperfeiçoamento em Gestão Pública na percepção dos gestores Técnico-Administrativos em Educação de uma instituição pública de educação, ciência e tecnologia do Nordeste do Brasil. Trata-se de uma pesquisa qualitativa, com modo de investigação no estudo de caso e de objetivo descritiva. Para o levantamento dos dados utilizou-se de entrevista estruturada por meio do MAIS (Modelo de Avaliação Integrado e Somativo), proposto por Jairo BorgesAndrade, Gardênia Abbad e Luciana Mourão. Os dados coletados foram tratados em planilhas eletrônicas e os resultados demonstram que: quanto ao suporte organizacional, existiram condições organizacionais favoráveis e havia compromisso da organização com a aprendizagem das novas competências dos trabalhadores, bem como, houve a absorção pelos indivíduos/ grupos de trabalho sobre o quanto a organização valoriza suas contribuições de novos conhecimentos. Quanto ao impacto do treinamento, tem-se que ficou constatado que houve melhorias no desempenho individual dos servidores treinados através de uma nova forma de desempenhar antigas tarefas a partir das novas competências adquiridas.

PALAVRAS-CHAVE: Suporte, Impacto, Trabalhadores do conhecimento, Ciência, Tecnologia.

\section{EVALUATION OF PROFESSIONAL TRAINING FOR KNOWLEDGE WORKERS: a case study at a public institution of education, science and technology in Northeast Brazil}

\section{ABSTRACT}

The objective of this research was to evaluate the organizational support for learning and the impact of the Course on Improvement in Public Management in the perception of the Technical-Administrative managers in Education of a public institution of education, science and technology of the Northeast of Brazil. It is a qualitative research, with a mode of investigation in the case study and a descriptive objective. For the data collection it was used a structured interview through the ISAM (Integrated and Summative Assessment Model), proposed by Jairo Borges-Andrade, Jardim Abbad and Luciana Mourão.
The data collected were processed in electronic spreadsheets and the results show that: in terms of organizational support, there were favorable organizational conditions and there was commitment of the organization to the learning of the new skills of the workers, as well as the absorption by the individuals / work groups about how much the organization values its contributions of new knowledge. As for the impact of the training, it has been verified that there were improvements in the individual performance of the trained servants through a new way of performing old tasks from the new skills acquired.

KEYWORDS: Support, Impact, Knowledge Workers, Science, Technology. 


\section{INTRODUÇÃO}

A chegada do século XXI foi marcada por muitas características: o mundo globalizado, o crescente avanço tecnológico, a formação de grandes conglomerados empresariais, a mudança no comportamento do consumidor, a internacionalização das organizações, bem como questões de ordem social e política (Abranches, 2017) e a emergência de uma nova sociedade que se convencionou chamar de Sociedade do Conhecimento.

A sociedade do conhecimento abriu novas portas de produção através do conhecimento incorporado a produtos, serviços, processos, tomadas de decisão, modelos de gestão, gerando-se a inovação tecnológica tanto para organizações privadas como públicas, porém acentuou-se mais a exclusão social dos trabalhadores, entendendo-se a produção como a geradora de oportunidades. Pois nesse contexto, quem conhece mais possui maior facilidade para realizar transformações e criações, favorecendo-se novas oportunidades de trabalho e/ou de manutenção no emprego ou o efeito contrário.

Portanto, cresceu a importância nas organizações pelo conhecimento dos trabalhadores, pois passaram a propiciar atividades em grupo e para criação e acúmulo de conhecimento em nível individual e organizacional. Uma das ações utilizadas pelas organizações, apesar de ser uma atividade operacional, mas que tem enfoque estratégico são os programas de treinamento, desenvolvimento e educação (TD\&E) para a organização e o trabalho.

Os processos de TD\&E buscam atualizar e viabilizar mudanças substantivas e qualitativas dos conhecimentos relacionados à área de competência essencial das organizações, que no caso da instituição pesquisada neste artigo - de educação, ciência e tecnologia -, envolve conhecimentos das áreas de: educação, administração, gestão pública, pedagogia, serviço social, contabilidade, química, biocombustíveis, agricultura, zootecnia, veterinária, biologia, matemática, física, inglês, espanhol, geografia, história, direito, informática e sistemas de comunicação. Saberes estes, que estão em evolução e aperfeiçoamento contínuo e que são fundamentais para beneficiar a sociedade local e promover o desenvolvimento regional.

Portanto, os programas de treinamento e educação profissional buscam facilitar a disseminação do conhecimento, assim como o caso pesquisado, que trata da avaliação de suporte organizacional e do impacto do Curso de Aperfeiçoamento em Gestão Pública para os gestores da organização pesquisa, pois este tipo de educação é um ambiente preparados para conversão do conhecimento tácito - adquirido com a experiência e erro, em conhecimento explícito, manualizado, de forma que todos possam ter acesso. Além disso, possibilitam o treino das habilidades sociais das pessoas, que pode torná-los mais competentes para desempenhar vários papéis e aptos para resolução dos problemas do dia a dia organizacional. E para que isso ocorra os trabalhadores precisam receber apoio da organização para aplicar os conhecimentos aprendidos e as habilidades treinadas, e para que haja impacto na resolução dos problemas e a incorporação do conhecimento nos produtos, serviços, tomada de decisão, no planejamento, entre outros.

Diante disse contexto tem-se as seguintes questões de pesquisa: a educação profissional (treinamento) oferecida no âmbito de uma instituição pública de educação, ciência e tecnologia, a partir do Curso de Aperfeiçoamento em Gestão Pública, teve impacto (tornou os trabalhadores do conhecimento e a organização mais competentes) para a resolução dos problemas do dia a 
dia? Os trabalhadores-servidores tiveram suporte organizacional para a transferência e utilização do conhecimento e das habilidades aprendidas?

O objetivo da pesquisa foi avaliar o suporte organizacional para aprendizagem e o impacto do Curso de Aperfeiçoamento em Gestão Pública na percepção dos gestores TécnicoAdministrativos em Educação de uma instituição pública de educação, ciência e tecnologia do Nordeste do Brasil.

A pesquisa se justifica, pois há uma crescente demanda por avaliação dos programas de educação corporativa nas organizações já que se trata de uma importante estratégia para criar uma cultura de transferência do conhecimento e desenvolver as competências dos trabalhadores. A instituição pública pesquisada tem como seu principal recurso o conhecimento, pois se trata de uma organização de educação formal, portanto eleva-se a importância do impacto da educação para o trabalho, bem como da necessidade do desenvolvimento das competências necessárias para aperfeiçoamento do fazer institucional em prol do desenvolvimento regional.

Além disso, a expansão e interiorização das instituições federais de ensino no país e no Nordeste do Brasil incorre em um novo desafio: a ampliação da atuação da rede federal, mantendo-se a qualidade da ação educacional e a eficiência administrativa de forma descentralizada. Posto isto, considera-se a necessidade de consolidar bases mais consistentes de conhecimento para a atuação administrativa descentralizada das instituições federais de ensino que podem ser viabilizadas pela educação corporativa para a construção de relacionamentos e confiança mútua entre os servidores; estabelecer um consenso através da educação, discussão, publicações; trabalhos em equipe; desenvolver a capacidade de flexibilidade; a assertividade; a motivação; propiciar tempo e espaço adequado para aprendizagem em grupo e, consequentemente desenvolver as competências dos trabalhadores-servidores e a qualificação do trabalho. A avaliação de treinamento ainda pode mensurar medidas dos esforços despendidos nestas ações que efetivamente geraram os efeitos desejados, tanto para os servidores quanto para a organização.

Além da introdução, a pesquisa explora no referencial teórico a perspectiva conceitual dos modelos de trabalho, dos trabalhadores do conhecimento e a necessidade do desenvolvimento de competências a partir de atividade de treinamento e educação profissional com foco em avaliação. Utilizou-se dos componentes Suporte Organizacional e Impacto do instrumento MAIS (Modelo de Avaliação Integrado e Somativo), proposto por Borges-Andrade, Abbad \& Mourão (2009) para consecução do objetivo traçado. Após o referencial teórico, tem-se a metodologia, a análise dos resultados, as considerações finais e as referências.

\section{FUNDAMENTOS TEÓRICOS}

Preparar as organizações para o futuro não tem sido uma tarefa fácil, pois a velocidade da mudança que está acontecendo em todo mundo é assustadora. Porém, para se manterem competitivas no mercado, as organizações iniciaram um novo ciclo de transformações, dentro do processo de mundialização do capital, mediante a reestruturação produtiva para se manterem e se expandirem no mercado. (Senge, 1999).

A maioria dos esforços empreendidos pelo capital para manter sua hegemonia sobre o trabalho, tais como: o planejamento estratégico, gestão da qualidade, reestruturação, reengenharia, downsizing, flexibilização, terceirização e reorganização do trabalho - de 
funcionalista/especializado para gestão por processos, virtual e redes - não tinham trazido os resultados esperados pelos executivos. Nesse momento, se sentiu a necessidade de estudar/pesquisar, principalmente por parte dos pesquisadores ocidentais, os princípios e a forma de funcionamento que orientavam as organizações que sobreviviam no mercado, entre elas as organizações orientais (Nonaka \& Takeuchi, 2004).

De acordo com Brito (2005), os resultados desses estudos mostraram que: as organizações que apresentavam lucro, que se expandiam no mercado e se projetavam para o futuro, tinham "aprendido a aprender" a se adaptarem com rapidez às demandas do mercado e apresentavam como características marcantes a gestão de sua competência essencial, a gestão do conhecimento necessário para projetar a empresa para o futuro e a tentativa de mudar/ revitalizar sua cultura organizacional.

Para Bukowitz \& Williams (2002), a ciência da administração passou a perceber os modelos chamados baseados no conhecimento, caracterizados por estruturas flexíveis, voltados para clientes e fornecedores, valorização das pessoas com conhecimento e competências estratégicas para o negócio, uso de tecnologias da informação (TI), da comunicação e do conhecimento. Nesse contexto, inicia-se nos anos 90 a discussão sobre competências de cunho estratégico, que na verdade se complementa com outras matrizes que estão gerando o novo modelo de gestão do trabalho em construção na atualidade em substituição aos modelos burocráticos, ou seja, faz parte de um grande movimento que tem como outras matrizes fundamentais: a Gestão do Conhecimento - cujo foco é o gerenciamento do conhecimento mapear, captar, disseminar, reter, construir, avaliar, recompensar e descartar, (Nonaka \& Takeuchi, 2004; Drucker \& Howard, 2000; Sveiby, 1998), e as organizações de aprendizagem que tratam da mudança da cultura organizacional (Senge, 2012) - de especialista funcionalista para orgânica, virtual e flexível.

Essas mesmas mudanças e novos modelos de gestão, também se aplicam ao setor público, a diferença é que: nas organizações privadas, se não inovarem tendem a desaparecer com uma maior rapidez; as organizações públicas são motivadas a buscar esse novo cenário para lidar com as pressões legítimas de uma sociedade cada vez mais exigente.

Portanto, o conhecimento, independente do setor econômico passa a ser definido como essencial para o sucesso das organizações e se define como uma combinação de experiência, valores, informações e insights experimentados por uma pessoa que leva à incorporação e avaliação de novas experiências e outras informações, que são aperfeiçoadas com o uso (Davenport \& Prusak, 1998). Assim, as organizações estão sendo compelidas a melhorar e cuidar do conhecimento interno existente na mente dos seus empregados, como um novo tipo de ativo empresarial. Outra característica dos novos modelos de gestão do trabalho, é que tem como ponto principal o indivíduo, ou seja, as pessoas passam a figurar como os principais ativos estratégicos - as pessoas e suas competências, já que o conhecimento reside nas pessoas e é na sua interação, ou seja, através das habilidades das pessoas (inteligência, sensibilidade, discernimento, criatividade e capacidade de inovação), que ele - o conhecimento é disseminado provocando-se a aprendizagem organizacional. A esses indivíduos Drucker \& Howard (2000) atribuiu o nome de trabalhadores do conhecimento, abordado em seguida.

\subsection{Trabalhadores do conhecimento e suas competências}

O trabalhador do conhecimento é um executivo do conhecimento que sabe alocar o conhecimento para uso produtivo, da mesma forma que o capitalista sabe alocar o capital para 
uso produtivo. (Drucker \& Howard, 2000). São pessoas fiéis, que extraem o conhecimento daqueles que o têm, colocam esse conhecimento numa forma estruturada, filtram, disseminam, ajudam a incorporá-lo a produtos serviços e na tomada de decisão, ou o aprimoram ao longo do tempo, para que possam manter a organização viável no futuro.

Bons trabalhadores do conhecimento, de qualquer nível, deveriam ter uma combinação de competências hard (conhecimento estruturado, qualificações técnicas e experiência profissional) e de atributos soft (um claro senso dos aspectos culturais, políticos e pessoais do conhecimento). (Davenport \& Prusak, 1997).

Portanto, o êxito das organizações no mercado e na sociedade pode ser obtido se elas estiverem baseadas nas competências, na criatividade e nas atividades agregativas de valor dos trabalhadores, criando-se assim, em nível organizacional suas core competências, no caso do mercado, e valor público, no caso da sociedade, que poderão diferenciá-las, assim como ocorreu com as organizações japonesas na década de noventa (Nonaka \& Takeuchi, 2004), pois, conforme coloca Sveiby (1998, p. 11) "a competência do funcionário envolve a capacidade de agir em diversas situações para criar tanto ativos tangíveis como intangíveis". A competência está relacionada com a escolaridade, a capacidade de solucionar as incertezas do dia-a-dia através da arte de "saber fazer" que envolve a proficiência prática - física e mental - experiência, visto que esta será a base para a construção de novos conhecimentos. (Tavares, 2010; Brito, 2005).

A partir do referencial teórico tratado até aqui, apregoa-se então, no plano dos indivíduos, a noção de que, contemporaneamente, chegou a oportunidade das pessoas se libertarem das rígidas estruturas organizacionais, da alta especialização, podendo se desenvolver através de suas competências buscando-se as multi habilidades profissionais (Brito, 2008) em instituições flexíveis, horizontalizadas, através do trabalho cooperativo e em equipes complementares.

Para Castro, Brito \& Varela (2017); Brito (2005), isso passa pela ressignificação do papel dos recursos humanos $(\mathrm{RH})$ que adquire novos nomes - gestão de pessoas, gestão do capital humano, gestão do capital intelectual etc. A ressignificação do $\mathrm{RH}$ se torna vital, pois passa a ter um papel ativo nas escolhas estratégicas das empresas, especialmente no tocante à preparação dos talentos para as mudanças, e uma das estratégias mais utilizadas segundo Meister \& Willyerd (2013); Meister (1999) são os processos de TD\&E que envolvem diversos métodos e técnicas, entre elas: palestras, leituras, audiovisual, demonstrações, cursos, oficinas, simpósios, congressos, semanas, grupos de discussão, praticar fazendo, ensinar aos outros/uso imediato, entre outras.

\subsection{Treinamento para o desenvolvimento das competências dos trabalhadores do conhecimento}

Os programas de treinamento, de acordo com Brito (2008), tem como objetivo maior tornar as organizações mais eficazes e consequentemente desenvolver as habilidades organizacionais - as core competências, e individuais. Portanto, como asseveram vários estudiosos do tema (Meister \& Willyerd, 2013; Tasca, Ensslin \& Ensslin, 2011; Borges-Andrade et al., 2009; França, 2008; Lingham, Richley \& Rezania, 2006; Meister, 1999), as ações de treinamento e educação profissional são caracterizadas pela intencionalidade de produzir um conjunto de efeitos que podem estar descritos nas próprias estratégias organizacionais, ou seja, essas ações precisam estar alinhadas às estratégias organizacionais (missão/ função social, visão, 
objetivos, planejamento, entre outras) visando-se a integração entre os interesses da organização e das pessoas, é o que se apregoa.

Portanto, tornou-se consenso de que qualquer profissional que queira garantir sua sobrevivência no mercado deve apegar-se à ideia de atualização constante na busca das competências requeridas pelas organizações. (Roggero, 2003). Caso contrário, aqueles que não possuem um preparo adequado ao cargo estão mais propensos, tanto a tomada de decisão incorreta e a frequentemente culpar terceiros por suas falhas, quanto a substituição por outros profissionais melhor qualificados/competentes. (França, 2008; Brito, 2005). Por outro lado, mobiliza as organizações, que requerem de seus funcionários qualificações mais amplas, habilidades mais diversificadas, aprendizagem continuada e habilidades do saber fazer. (Meister, 1999).

De acordo com Von Krogh, Ichijo \& Nonaka (2001), o treinamento faz parte das estratégias de criação de condições facilitadoras, cria tempo e local para criação do conhecimento organizacional, pois favorecem o aprendizado e disseminação de informações através das habilidades das pessoas.

Portanto, os programas de TD\&E além de ajudar a criar uma cultura de transferência do conhecimento, desenvolver estratégias cognitivas e atitudes que poderão tornar os indivíduos mais competentes para desempenhar vários papéis, também corroboram para melhorar processos, usar novas tecnologias, converter conhecimento tácito em explícito e, sobretudo criar ambientes que favoreçam a inovação. (Tasca et al., 2011; Medeiros \& Levi, 2010; Borges-Andrade et al., 2009; Von Krogh, Ichijo \& Nonaka, 2001). A partir desse contexto, entende-se que os programas de TD\&E para o trabalho são estratégias intencionalmente planejadas pelas organizações para: facilitar a socialização do conhecimento tácito e explícito, e desenvolver competências individuais alinhadas às estratégias organizacionais. Nesse sentido, mensurar o suporte organizacional e o impacto da ação Curso de Aperfeiçoamento em Gestão Pública significa avaliar em que medida os esforços despendidos neste treinamento efetivamente geraram valor público para a sociedade.

\subsection{Avaliação de Suporte Organizacional e Impacto de Treinamento Profissional}

De acordo com Borges-Andrade et al. (2009) a avaliação de TD\&E, pode ser definida como um processo que inclui sempre algum tipo de coleta de dados usados para se emitir um juízo de valor a respeito de um evento de TD\&E ou mensurar seu impacto. São perguntas frequentemente discutidas nas organizações: o desempenho das pessoas treinadas mudou? Houve aperfeiçoamento? Os ganhos esperados em termos de competências, competitividade, lucros, processos, clima, foram alcançados? Como podemos atribuir ao evento de TD\&E a responsabilidade por gerar esses efeitos? Assim, mensurar significa avaliar se houve melhoria no desempenho dos indivíduos, dos grupos e da organização.

É o que ratificam Bastos (1994); Alves \& Tamayo (1993) quando colocam que a avaliação de treinamento é o processo pelo qual se estabelece a validade dos objetivos finais de um programa instrucional (os objetivos parciais devem ter sido avaliados passo a passo) a partir de seus resultados no desempenho dos trabalhadores e consequentemente da organização, e a avaliação torna-se o único processo capaz de assegurar ao treinamento uma posição relevante perante a área fim da organização.

Portanto, a avaliação de treinamento é o processo de validação dos efeitos planejados, frente aos resultados alcançados no desempenho dos trabalhadores na organização. Nesse 
sentido, vários autores ao longo do tempo empreenderam esforços para a construção de medidas para avaliação de treinamento, entre eles os descritos no Quadro 1, em seguida.

Quadro 1. Modelos de Medidas de Avaliação de Treinamento.

\begin{tabular}{|c|c|c|}
\hline Autores & Ano & Ferramentas \\
\hline Tasca et al. & 2011 & $\begin{array}{l}\text { Utilizaram a Metodologia Multicritério de Apoio à Decisão - Construtivista (MCDA- } \\
\text { C) para avaliação de programas de capacitação desenvolvidos na administração } \\
\text { pública. }\end{array}$ \\
\hline Westbrook et al. & 2008 & $\begin{array}{l}\text { Utilizaram um survey e escalas médicas predefinidas para avaliar o aprendizado } \\
\text { gerado. }\end{array}$ \\
\hline $\begin{array}{l}\text { Borges-Andrade et } \\
\text { al. }\end{array}$ & 2009 & Modelo de Avaliação Integrado e Somativo (MAIS). \\
\hline $\begin{array}{l}\text { Lingham, Richley \& } \\
\text { Rezania }\end{array}$ & 2006 & Four-phase Evaluation System (Sistema de Avaliação em Quatro Fases). \\
\hline $\begin{array}{l}\text { Grammatikopoulos } \\
\text { et al. }\end{array}$ & 2004 & Guskey's Modelo of Five Levels (Modelo Guskey de Cinco Níveis). \\
\hline Featherstone et al. & 2004 & $\begin{array}{l}\text { Utilizaram uma avaliação para verificar a efetividade de um curso por meio da } \\
\text { comparação entre um grupo experimental (participantes) com um grupo de } \\
\text { controle (não participantes). }\end{array}$ \\
\hline $\begin{array}{l}\text { Litarowsky, Murphy } \\
\text { \& Canham }\end{array}$ & 2004 & $\begin{array}{l}\text { Pre-experimental design with a pretest and posttest (Projeto Pre-experimental com } \\
\text { um pré-teste e um pós-teste. }\end{array}$ \\
\hline Wong \& Wong & 2003 & $\begin{array}{l}\text { Kirkpatrick's Model - Four-Level Evaluation Model (Modelo Kirkpatrick - quatro } \\
\text { níveis Modelo de Avaliação). }\end{array}$ \\
\hline $\begin{array}{l}\text { Tennant, Boonkrong } \\
\text { \& Roberts }\end{array}$ & 2002 & $\begin{array}{l}\text { Training Programme Measurement Model (Modelo de Mensuração de Programa de } \\
\text { Treinamento). }\end{array}$ \\
\hline $\begin{array}{l}\text { McMillan, Bunning \& } \\
\text { Pring }\end{array}$ & 2000 & $\begin{array}{l}\text { Utilizaram uma avaliação para verificar a efetividade de um treinamento por meio } \\
\text { da comparação entre um grupo experimental com um grupo de controle. }\end{array}$ \\
\hline $\begin{array}{l}\text { Kuprenas, Madjidi \& } \\
\text { Alexander }\end{array}$ & 1999 & $\begin{array}{l}\text { Multiple-level Training Assessment Process (Processo de Avaliação de Treinamento } \\
\text { em vários níveis). }\end{array}$ \\
\hline Campbell & 1998 & Evaluation Schema (Esquema de avaliação). \\
\hline Kirkpatrick & 1994 & $\begin{array}{l}\text { Propõe quatro níveis de avaliação de treinamento, sendo: Reação, Aprendizagem, } \\
\text { Comportamento e Resultados. }\end{array}$ \\
\hline Alves \& Tamayo & 1993 & $\begin{array}{l}\text { Sistema de Avaliação do Treinamento - SAT, a partir de três critérios: aprendizado, } \\
\text { reação e melhoria da qualidade de desempenho no trabalho. }\end{array}$ \\
\hline
\end{tabular}
Fonte: Adaptado de Tasca et al., (2011).

Diante desses modelos, considerando-se o objetivo da pesquisa, optou-se pela abordagem de Borges-Andrade et al. (2009) que propõem o Modelo de Avaliação Integrado e Somativo (MAIS) como o objetivo de "obter informações para avaliar um programa já desenvolvido, visando verificar a capacidade deste de produzir resultados" (p. 345), sendo focados os componentes Suporte Organizacional e Impacto, conforme Quadro 2.

No senso comum, "suporte" se trata segundo Ferreira (1993), daquilo que presta apoio e que dá sustentação. Conforme Borges-Andrade et al. (2009, p. 396), na linguagem técnica, "suporte é empregado de modo similar para expressar condições organizacionais favoráveis de trabalho e, em alguns casos, ao compromisso da organização para com o indivíduo", ou seja "em termos de programas de TD\&E, o que a organização deve oferecer como suporte para a aplicação no trabalho de novas competências, habilidades e atitudes?". A percepção de suporte, portanto trata da absorção, pelos indivíduos, dos estímulos fornecidos pela organização sobre o quanto ela valoriza as suas contribuições, que para efeito da avaliação da ação de TD\&E, refere-se à avaliação da influência que os fatores organizacionais exercem sobre a aprendizagem dos indivíduos. 
Já o "impacto", conforme Abbad, Pilati \& Pantoja (2003), pode ser compreendido à luz dos conceitos de transferência de treinamento e de desempenho individual no trabalho, pois "aquilo que o participante transfere ou aplica no trabalho é uma nova forma de desempenhar antigas tarefas e/ou, por outro lado, um novo tipo de desempenho que nunca antes havia sido exibido". (Borges-Andrade et al., 2009, p. 490). Portanto, impacto é principalmente associado a mudança na forma de desempenhar tarefa similar àquela aprendida no treinamento.

Quadro 2. Conceito das variáveis de avaliação de treinamento

\begin{tabular}{|c|c|c|c|}
\hline Variáveis & $\begin{array}{l}\text { Componente } \\
\text { do Modelo }\end{array}$ & Nível de Suporte & Foco \\
\hline $\begin{array}{l}\text { Suporte } \\
\text { Psicossocial à } \\
\text { Transferência }\end{array}$ & \multirow{4}{*}{$\begin{array}{c}\text { Suporte } \\
\text { Organizacional }\end{array}$} & $\begin{array}{c}\text { Relacionamento dos } \\
\text { trabalhadores com a chefia } \\
\text { imediata e os grupos de trabalho }\end{array}$ & \multirow{2}{*}{$\begin{array}{l}\text { Trata da investigação da influência do } \\
\text { ambiente gerencial/ interpessoal pós- } \\
\text { treinamento ao uso das habilidades } \\
\text { aprendidas }\end{array}$} \\
\hline $\begin{array}{l}\text { Suporte } \\
\text { Material à } \\
\text { Transferência }\end{array}$ & & $\begin{array}{l}\text { Relacionamento da organização } \\
\text { para com os trabalhadores e com } \\
\text { os grupos de trabalho }\end{array}$ & \\
\hline $\begin{array}{l}\text { Suporte à } \\
\text { Aprendizagem } \\
\text { Contínua }\end{array}$ & & Grupos de trabalho & $\begin{array}{l}\text { Percepção do indivíduo sobre as } \\
\text { condições necessárias à aprendizagem no } \\
\text { grupo de trabalho }\end{array}$ \\
\hline $\begin{array}{l}\text { Suporte à } \\
\text { Aprendizagem }\end{array}$ & & $\begin{array}{l}\text { Relacionamento com a chefia } \\
\text { imediata, os colegas de trabalho e } \\
\text { grupos de trabalhos }\end{array}$ & $\begin{array}{l}\text { Trata do apoio ou restrição dos pares à } \\
\text { aprendizagem e transferência das novas } \\
\text { habilidades aprendidas }\end{array}$ \\
\hline $\begin{array}{l}\text { Medida de } \\
\text { Impacto do } \\
\text { Treinamento } \\
\text { em Largura ou } \\
\text { Amplitude }\end{array}$ & Impacto & Individual & $\begin{array}{l}\text { Trata dos resultados do treinamento em } \\
\text { termos comportamentais através das } \\
\text { competências, habilidade e atitutdes } \\
\text { previstas no programa da capacitação do } \\
\text { nível individual ao organizacional }\end{array}$ \\
\hline
\end{tabular}

Fonte: Adaptado de Borges-Andrade et al. (2009).

A consolidação desta pesquisa poderá ser melhor compreendida por meio dos procedimentos metodológicos e da análise dos resultados que se seguem.

\section{METODOLOGIA}

Trata-se de uma pesquisa qualitativa (Merriam, 1998), com modo de investigação no estudo de caso (Yin, 2015), com objetivo descritivo.

Para a avaliação do suporte organizacional a população compreendeu os 17 servidores Técnicos-Administrativos em Educação (TAE) participantes do Curso de Aperfeiçoamento em Gestão Pública realizado em um campus de uma instituição de educação, ciência e tecnologia do Nordeste do Brasil durante o período de 29 de novembro de 2011 a 5 de outubro de 2012. Para a avaliação do Impacto do treinamento, a população compreendeu 18 gestores (entre TAEs e docentes) ocupantes de Função Gratificada e/ou de Cargo de Direção envolvidos nos níveis tático e estratégico em atividade durante o período da capacitação.

A estratégia utilizada para a aplicação e coleta do instrumento de pesquisa para todo o público alvo foi a entrevista estruturada (Merriam, 1998) por meio da entrega e recebimento pessoal de questionário impresso. $O$ instrumento de coleta de dados que foi utilizado para atingir os objetivos desse estudo foi o MAIS - Modelo de Avaliação Integrado e Somativo, questionário validado metodologicamente pelos autores Borges-Andrade et al. (2009), sendo utilizadas as 
seguintes variáveis: Suporte Psicossocial à Transferência, Suporte Material à Transferência, Suporte à Aprendizagem Contínua, Suporte a Aprendizagem e Medida de Impacto do Treinamento em Largura ou Amplitude. O questionário utilizado continha 31 (trinta e uma) questões fechadas. Também foi utilizado um questionário de levantamento de dados sociodemográficos.

A escala utilizada continha para o MAIS era de 5 (cinco) pontos variando-se de 'sempre' a 'nunca' e todos os itens do questionário foram tabulados utilizando-se planilhas eletrônicas, obtendo-se os cruzamentos entre as variáveis de interesse para análise, que são apresentadas através de tabelas com as médias percentuais.

Nesse sentido, Godoy (1995, p. 26), esclarece que "ainda que os estudos de caso sejam, em essência, pesquisa de caráter qualitativo, podem comportar dados quantitativos para aclarar algum aspecto da questão investigada. É importante ressaltar que, quando há análise quantitativa, geralmente o tratamento estatístico não é sofisticado".

Visando-se o aprofundamento da pesquisa, foram atribuídos indicadores às questões utilizadas do modelo relacionadas ao Suporte Organizacional e Impacto do treinamento. A categorização dos itens avaliativos (questões do questionário de pesquisa) em indicadores possibilita identificar o que mais concorreu, ou o contrário, para os resultados encontrados na avaliação do processo do treinamento.

Quadro 3. Indicadores de Suporte Organizacional e Impacto do treinamento.

\begin{tabular}{|c|c|c|c|}
\hline Componente & Indicadores & $\begin{array}{c}\text { Itens } \\
\text { avaliativos }\end{array}$ & Conceito \\
\hline \multirow{4}{*}{$\begin{array}{l}\text { Suporte } \\
\text { Organizacional }\end{array}$} & Chefia Imediata & $\begin{array}{l}3,4,7,17 \\
18,19,20\end{array}$ & $\begin{array}{l}\text { A chefia imediata encoraja, cria oportunidades e dá autonomia } \\
\text { para o uso de novas habilidades aprendidas no treinamento. }\end{array}$ \\
\hline & $\begin{array}{ll}\text { Recursos } & \\
\text { Materiais } & / \\
\text { Equipamentos e } \\
\text { Ferramentas }\end{array}$ & $8,9,10,11$ & $\begin{array}{l}\text { A organização tem viabilizado através da disponibilização de } \\
\text { equipamentos, materiais e ferramentas de trabalho o uso de } \\
\text { novas habilidades aprendidas no treinamento. }\end{array}$ \\
\hline & $\begin{array}{l}\text { Relações Sociais } \\
\text { no Trabalho }\end{array}$ & 13,21 & $\begin{array}{l}\text { Os colegas de trabalho buscam através da interação viabilizar a } \\
\text { aprendizagem no trabalho, mesmo quando há dificuldade de } \\
\text { aprendizagem. }\end{array}$ \\
\hline & $\begin{array}{l}\text { Socialização do } \\
\text { Conhecimento }\end{array}$ & $\begin{array}{l}5,6,12,14 \\
15,16\end{array}$ & $\begin{array}{l}\text { A chefia imediata e os colegas de trabalho buscam viabilizar a } \\
\text { aprendizagem a partir das pessoas mais experientes e das } \\
\text { experiências bem sucedidas dos outros setores da instituição. } \\
\text { Além disso, as informações necessárias para trabalhar estão } \\
\text { disponíveis e existe estímulo para o compartilhamento de } \\
\text { novos conhecimentos. }\end{array}$ \\
\hline \multirow[t]{2}{*}{ Impacto } & $\begin{array}{l}\text { Qualidade } \\
\text { Eficiência } \\
\text { trabalho }\end{array}$ & $\begin{array}{l}24,26,27, \\
28\end{array}$ & $\begin{array}{l}\text { As competências, habilidades e atitudes aprendidos no } \\
\text { treinamento possibilitaram que os trabalhadores cometessem } \\
\text { menos erros e executassem com mais rapidez as mesmas } \\
\text { atividades, mesmo aquelas que pareciam não estar } \\
\text { relacionadas diretamente com o conteúdo do treinamento. }\end{array}$ \\
\hline & $\begin{array}{l}\text { Motivação para o } \\
\text { trabalho }\end{array}$ & $\begin{array}{l}22,23,25 \\
29,30,31 \\
32,33\end{array}$ & $\begin{array}{l}\text { A participação dos trabalhadores no treinamento aumentou } \\
\text { sua motivação e autoconfiança na execução das novas } \\
\text { habilidades e socialização do conhecimento. }\end{array}$ \\
\hline
\end{tabular}

Fonte: Adaptado de Borges-Andrade et al. (2009). 
A validade e a confiabilidade interna da pesquisa foram aferidas por meio da avaliação de pares pesquisadores da área. A validade externa da pesquisa está na descrição rica e densa que buscou compreender em profundidade a percepção de um grupo de sujeitos, evitando-se formas de generalização dos achados para a população (Merriam, 1998).

\section{O ESTUDO DE CASO}

A função social da instituição pesquisada é promover a educação científico-tecnológicohumanística visando à formação integral do profissional-cidadão. O Campus de uma instituição pública de educação, ciência e tecnologia do Nordeste do Brasil pesquisado, fez parte da segunda fase de expansão da rede federal tendo entrado em funcionamento em Setembro de 2009. No contexto da instituição pesquisada, para viabilizar a consecução da função social e dos objetivos descritos, ela conta com um quadro total de 35 servidores Técnico-Administrativos em Educação e 60 Docentes. (Cogpe, 2011; Política de Capacitação, 2005).

A Gestão de Pessoas no âmbito do Governo Federal tem entre suas diretrizes o desenvolvimento permanente do servidor público. Para isso, valoriza as diversas formas de aprendizagem (presencial, a distância, visitas técnicas, entre outros), pois é o que preconiza a Política Nacional de Desenvolvimento de Pessoal (Decreto no 5.707/06, regulamentado pela Portaria no 208/06). De acordo com Medeiros \& Levy (2010, p. 193), essa política visa:

[...] à melhoria da eficiência e da eficácia do serviço público. Considera fundamental a adequação das competências requeridas aos objetivos das instituições. Suas estratégias de implementação são: gestão por competências como referência da política; a priorização de capacitação das áreas de $\mathrm{RH}$ e dos ocupantes de cargos de direção e assessoramento superior; o reconhecimento do papel das escolas de governo; a criação do Comitê Gestor da Política que acompanha e orienta as ações de capacitação; o incentivo às iniciativas de capacitação promovidas pelas próprias instituições e a ampla divulgação das oportunidades.

$\mathrm{Na}$ instituição pesquisada, a partir das diretrizes do Governo Federal são adotadas as seguintes diretrizes de Gestão de Pessoas: desenvolver programas relacionados à melhoria da qualidade de vida do servidor e, fomentar programas de capacitação e estabelecimento de convênios e intercâmbios com instituições de ensino nacionais e internacionais, de modo a elevar a titulação dos servidores (Cogpe, 2011). Enquanto que no campus estudado, tem-se o recorte descrito no quadro 4.

Quadro 4. Políticas de Gestão de Pessoas para a educação, ciência e tecnologia

\begin{tabular}{|l|l|}
\hline \multicolumn{1}{|c|}{ Política de Gestão de Pessoas } & \multicolumn{1}{c|}{ Descrição } \\
\hline $\begin{array}{l}\text { Política de Acompanhamento, } \\
\text { planejamento e avaliação de } \\
\text { Pessoal }\end{array}$ & $\begin{array}{l}\text { Planejar, supervisionar, controlar, acompanhar e avaliar o pessoal, dimensionar a } \\
\text { força de trabalho e desenvolver e aperfeiçoar os processos de gestão de pessoas. }\end{array}$ \\
\hline $\begin{array}{l}\text { Política de Capacitação e } \\
\text { Incentivo a Qualificação }\end{array}$ & $\begin{array}{l}\text { Possibilitar cursos de formação inicial, formação continuada, aperfeiçoamento e } \\
\text { atualização em serviço em todos os níveis e modalidades de ensino, e fomentar } \\
\text { programas e convênios com IES para elevar a titulação dos servidores. }\end{array}$ \\
\hline $\begin{array}{l}\text { Política de Qualidade de Vida } \\
\text { e Integração Social }\end{array}$ & $\begin{array}{l}\text { Promover a qualidade de vida no trabalho mediante ações de integração e } \\
\text { sensibilização social. }\end{array}$ \\
\hline
\end{tabular}


Portanto, existe o reconhecimento da prática de capacitação tanto em nível do Governo Federal, quanto em nível do campus da instituição de ensino pesquisada, como um processo sistemático para promover a aquisição de habilidades, regras, conceitos e atitudes que busquem a melhoria da adequação entre as características dos empregados e as exigências dos papéis funcionais (França, 2008).

Quanto ao estudo de caso, com vistas ao objetivo proposto, utilizou-se do fluxograma proposto na Figura 1 para a viabilização do TD\&E relatado.

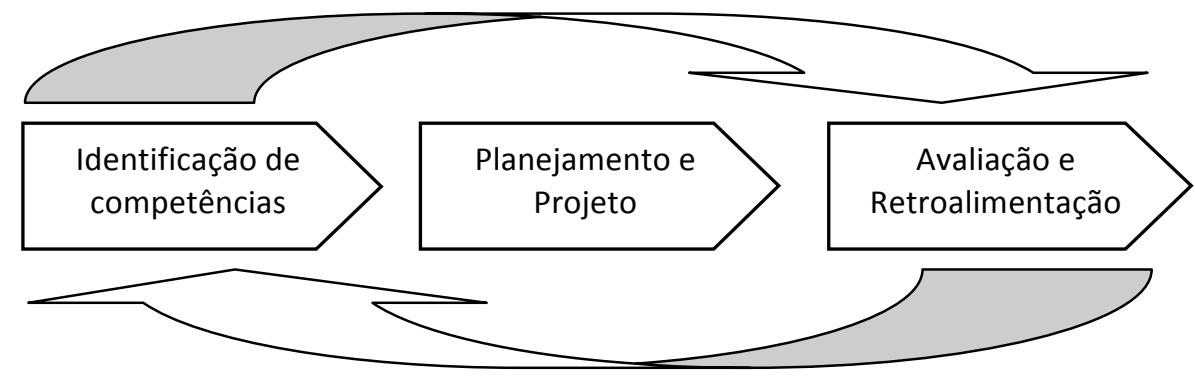

Figura 1. Fluxograma de construção de treinamento. Fonte: adaptado de Borges-Andrade et al. (2009); França (2008).

Do primeiro para o segundo passo da Figura 1, e deste para o terceiro, os referidos elementos mantem entre si um constante fluxo de informações, sendo que o subsistema "Avaliação e Retroalimentação" é o principal responsável pelo provimento de informações e, portanto, é o responsável pelo aperfeiçoamento constante do sistema. (França, 2008; BorgesAndrade et al., 2009). E seguida tem-se o detalhamento de cada passo:

a) Identificação de competências: Um dos primeiros procedimentos de um treinamento é identificar quais competências a organização necessita que os trabalhadores tenham para o desenvolvimento de sua função social, objetivos e estratégias. (França, 2008; Borges-Andrade et al., 2009). A construção das competências necessárias ao aperfeiçoamento ou desenvolvimento via processo de treinamento no campus da instituição pesquisada, foi definida em uma reunião de forma construtivista mediado pelo Diretor-Geral do campus pesquisado e por um administrador (Coordenador de Gestão de Pessoas) da instituição, juntamente ao público da pesquisa (TAEs e docentes ocupantes de Funções Gratificadas de Coordenação ou Cargos de Direção), sendo:

- Conhecimentos: planejamento, coordenação e controle; negociação; gestão das relações interpessoais no trabalho; qualidade de vida, saúde e segurança no trabalho; o novo perfil do servidor público e do serviço público federal; código de ética do servidor público; tecnologias da informação e da comunicação; gestão documental; processo administrativo no serviço público; gestão de materiais: almoxarifado e patrimônio público; legislação aplicada ao serviço público; correspondência e redação oficial; e, gestão financeira na administração pública;

- Habilidades: visão sistêmica, negociação, relacionamento interpessoal, qualificação continuada, transdisciplinariedade, cooperação e complementariedade, flexibilidade, trabalho em equipe e capacidade de delegação; e 
- Atitudes: zelo pelo patrimônio público, flexibilidade, objetividade, clareza e transparência, sensibilidade, ética, senso de servir e impessoalidade. (Cogpe, 2011).

b) Planejamento e projeto: É importante para garantir a eficácia dos resultados de $\mathrm{RH}$, quando devem ser programados: espaço físico, metodologia, objetivo, público alvo, facilitadores, cronograma de atividades e investimento. (Freire \& Pena, 1998). Além desses itens, França (2008) ainda incluir "resultados esperados", pois considera que, se existe um treinamento, é porque existe uma necessidade a ser suprida. Itens considerados por Borges-Andrade et al. (2009) como fatores de suporte à atividade de TD\&E. Através de um projeto técnico foram descritas respostas a cada item apontado pelos autores, sendo:

- Espaço Físico e material de escritório, didático e pedagógico: Sala de aula com computador com caixas de som, projetor multimídia, flip shart; Materiais didáticos (apostilas, cartolinas, papel madeira, papel A4, pastas, canetas, blocos, pincéis atômicos, quadro, tarjetas, entre outros); e, Laboratório de informática com 30 computadores e projetor multimídia;

- Metodologia - para desenvolver conhecimentos: curso modular presencial e participativo com aplicação de casos práticos de fixação do conteúdo; para desenvolver habilidades: utilização de simulações, apresentações de trabalhos, estudos em grupo e tarefas reais; para desenvolver atitudes: avaliação de desempenho (troca de atividades para avaliação dos pares), avaliação de apresentação dos grupos, avaliação do processo de formação profissional, tutoria de casos práticos.

- Objetivo: Capacitar os servidores com o propósito de contribuir para o seu desenvolvimento permanente na Instituição, visando o aperfeiçoamento do serviço público federal.

- Público Alvo: Servidores Técnico-Administrativos em Educação ocupantes de Funções Gratificadas de Coordenação ou Cargos de Direção;

- Facilitadores: Servidores da própria instituição com domínio e/ ou atuação na área de correlação direta com o tema da disciplina;

- Cronograma de atividades: de 29 de novembro de 2011 a 05 de outubro de 2012, conforme o quadro 5;

Quadro 5. Cronograma do Curso de Aperfeiçoamento em Gestão Pública

\begin{tabular}{|c|c|c|c|}
\hline Módulo & Eixo temático & Período & $\mathrm{CH}$ \\
\hline \multirow{3}{*}{ Módulo I } & $\begin{array}{l}\text { Gestão das relações } \\
\text { interpessoais no Trabalho }\end{array}$ & $29 / 11,30 / 11,01 / 12,06 / 12$ e $07 / 12 / 2011$ & $15 \mathrm{~h}$ \\
\hline & $\begin{array}{l}\text { Qualidade de Vida, Saúde e } \\
\text { Segurança no Trabalho }\end{array}$ & $08 / 12,13 / 12,14 / 12,15 / 12$ e $16 / 12 / 2011$ & $15 \mathrm{~h}$ \\
\hline & $\begin{array}{l}\text { O novo perfil do Estado e do } \\
\text { servidor público e a ética do } \\
\text { servidor no serviço público }\end{array}$ & $10 / 01,12 / 01,17 / 01$ e 19/01/2012 & $12 \mathrm{~h}$ \\
\hline \multicolumn{3}{|r|}{ SUB-TOTAL } & $42 \mathrm{~h}$ \\
\hline \multirow{3}{*}{$\begin{array}{l}\text { Módulo } \\
\text { II }\end{array}$} & $\begin{array}{l}\text { Informática aplicada ao } \\
\text { contexto de trabalho }\end{array}$ & $24 / 01,26 / 01,31 / 01,02 / 02,07 / 02,09 / 02$ e $14 / 02 / 2012$ & $21 \mathrm{~h}$ \\
\hline & $\begin{array}{l}\text { Correspondência e Redação } \\
\text { Oficial }\end{array}$ & $\begin{array}{c}28 / 02,01 / 03,06 / 03,08 / 03,13 / 03,15 / 03,20 / 03 \text { e } \\
22 / 03 / 2012\end{array}$ & $24 \mathrm{~h}$ \\
\hline & $\begin{array}{l}\text { Legislação do Serviço Público } \\
\text { Federal }\end{array}$ & $\begin{array}{l}27 / 03,29 / 03,03 / 04,05 / 04,10 / 04,12 / 04,17 / 04,19 / 04, \\
24 / 04,26 / 04,01 / 05,03 / 05,08 / 05,10 / 05 \text { e } 15 / 05 / 2012\end{array}$ & $45 h$ \\
\hline
\end{tabular}




\begin{tabular}{|c|c|c|c|}
\hline \multicolumn{3}{|r|}{ SUB-TOTAL } & $90 \mathrm{~h}$ \\
\hline \multirow{4}{*}{$\begin{array}{l}\text { Módulo } \\
\text { III }\end{array}$} & $\begin{array}{l}\text { Processo administrativo no } \\
\text { serviço público }\end{array}$ & $17 / 05,22 / 05,24 / 05,29 / 05 / 2012$ & $12 \mathrm{~h}$ \\
\hline & Gestão do protocolo & $31 / 05 / 2012$ & $3 \mathrm{~h}$ \\
\hline & $\begin{array}{l}\text { Gestão de Materiais: } \\
\text { Almoxarifado e Patrimônio }\end{array}$ & 05/06 e 07/06/2012 & $9 \mathrm{~h}$ \\
\hline & $\begin{array}{lll}\text { Gestão } \quad \text { Financeira } & \text { na } \\
\text { Administração Pública } & \\
\end{array}$ & $\begin{array}{c}\text { 12/06, 14/06, 19/06, 21/06, 26/06, 28/06, 03/07, 05/07, } \\
\text { 10/07, 12/07, 17/07, 19/07, 24/07 e 26/07/2012 }\end{array}$ & $43 \mathrm{~h}$ \\
\hline \multicolumn{2}{|c|}{ Avaliação Final do Curso } & $31 / 07 / 2012$ & $1 \mathrm{~h}$ \\
\hline \multicolumn{3}{|r|}{ SUB-TOTAL } & $68 \mathrm{~h}$ \\
\hline \multicolumn{3}{|c|}{$\begin{array}{c}\text { Bônus: Palestra sobre o Plano de Cargos e Carreiras dos Técnico-Administrativos em Educação (PCCTAE) } \\
\text { realizada em 05/10/2012 }\end{array}$} & $2 \mathrm{~h}$ \\
\hline \multicolumn{3}{|r|}{ TOTAL GERAL } & $202 \mathrm{~h}$ \\
\hline
\end{tabular}

Fonte: Cogpe (2011).

- Resultados Esperados: A aprendizagem organizacional, que é o conjunto da aprendizagem individual adquirido através do processo de aperfeiçoamento, que envolve a explicitação do conhecimento individual para os repositórios da organização para que sejam utilizados por todos para incorporação em novos produtos e serviços e na tomada de decisão. (Brito, Oliveira \& Castro, 2012). Além disso, Medeiros \& Levy (2010, p. 193), destacam como resultados esperados o que constam na política de desenvolvimento de pessoal do governo federal:

profissionais mais bem preparados e motivados, atentos à dinâmica da cidade e de seus conflitos; decisões ancoradas em informações (análise quantitativa e qualitativa); melhor dimensionamento de necessidades; desconcentração da operação e liberação de quadros da administração para outras atividades menos repetitivas; direitos de servidores assegurados; e incentivo à participação social para melhorar as decisões, com foco na inclusão.

c) Avaliação e retroalimentação: o processo de avaliação ocorreu após a realização do evento de TD\&E, como mecanismo estratégico de decisão ao grupo responsável sobre os investimentos a serem feitos que gerarão maior impacto no desempenho organizacional. Quanto a retroalimentação, o processo de Treinamento desenvolvido na organização baseia-se no plano de Gestão de Pessoas do campus estudado, conforme demonstrado no Quadro 4, e pressupõe a integração das atividades de treinamento com as áreas da atuação da instituição.

\section{RESULTADOS DO ESTUDO}

\subsection{Caracterização dos respondentes}

A maioria dos respondentes era do sexo masculino, com faixa etária entre 18 e 33 anos e com escolaridade de nível superior. Entre os participantes do curso, a maioria não havia participado anteriormente de capacitação de aperfeiçoamento para o trabalho, e todos se encontravam no nível de capacitação inicial da carreira e com cerca de 150 dias de tempo de serviço. Em relação aos gestores respondentes, a média de tempo de serviço na função era de aproximadamente 120 dias e ocupavam, em sua maioria Função Gratificada de Coordenação. 


\subsection{Resultados da avaliação do treinamento profissional: suporte organizacional}

Referente a avaliação do componente Suporte Organizacional ao treinamento feita pelos servidores TAEs participantes do Curso de Aperfeiçoamento em Gestão Pública, considerando-se os objetivos e a metodologia da pesquisa, percebeu-se, a partir da Tabela 1, que a organização 'sempre' ou 'muitas vezes' viabiliza o suporte organizacional. Significa dizer, conforme BorgesAndrade et al. (2009), que os resultados encontrados, tanto no nível dos relacionamentos entre os trabalhadores com suas chefias imediatas, quanto no relacionamento social (interpessoal, entre grupos de trabalho ou setores), bem como, da organização para com esses diversos níveis, 'sempre' ou 'muitas vezes' existem condições organizacionais favoráveis e compromisso da organização com a aprendizagem das novas competências, habilidades e atitudes pelos trabalhadores, bem como, sinaliza que existe a absorção pelos indivíduos/ grupos de trabalho sobre o quanto a organização valoriza suas contribuições de novos conhecimentos, e sobre a influencia positiva que o suporte organizacional exerce sobre a aprendizagem dos indivíduos favorecendo o desempenho positivo no trabalho.

Tabela 1. Resultado geral das ocorrências percentuais do componente Suporte Organizacional

\begin{tabular}{|l|c|c|c|c|c|}
\hline \multirow{2}{*}{ Variável } & \multicolumn{5}{c|}{ OCORRÊNCIAS EM PERCENTUAL } \\
\cline { 2 - 6 } & Nunca & Ocasionalmente & Com alguma frequência & Muitas Vezes & Sempre \\
\hline $\begin{array}{l}\text { Suporte Psicossocial à Transferência } \\
\text { de Treinamento }\end{array}$ & $0,00 \%$ & $7,06 \%$ & $8,24 \%$ & $36,47 \%$ & $48,24 \%$ \\
\hline $\begin{array}{l}\text { Suporte Material à Transferência de } \\
\text { Treinamento }\end{array}$ & $0,00 \%$ & $0,00 \%$ & $13,43 \%$ & $40,30 \%$ & $46,27 \%$ \\
\hline Suporte a Aprendizagem Contínua & $0,00 \%$ & $2,35 \%$ & $22,35 \%$ & $24,71 \%$ & $50,59 \%$ \\
\hline Suporte a Aprendizagem & $0,00 \%$ & $5,88 \%$ & $20,00 \%$ & $37,65 \%$ & $36,47 \%$ \\
\hline & $0,00 \%$ & $3,81 \%$ & $16,00 \%$ & $34,78 \%$ & $45,40 \%$ \\
\hline
\end{tabular}

Fonte: dados da pesquisa.

Em seguida tem-se a distribuição dos Indicadores do componente Suporte Organizacional, utilizados para o aprofundamento da análise dos dados.

\subsection{Indicadores de suporte organizacional ao treinamento}

A partir da necessidade de aprofundamento da analise dos resultados através de indicadores de Suporte Organizacional tem-se, conforme a Tabela 2, que a "Chefia Imediata" 'sempre' ou 'muitas vezes', encoraja, elogia, dá autonomia, assume os riscos e cria oportunidades para aplicar e planejar com os trabalhadores o uso das novas habilidades aprendidas no treinamento. Significa, portanto, que o suporte prestado pela chefia imediata como representante da organização para os trabalhadores do conhecimento viabiliza a transformação do conhecimento tácito em explicito, e esse é o norte da gestão do conhecimento nas organizações contemporâneas (Nonaka \& Takeuchi, 2004), ou seja, a organização está fornecendo condições facilitadoras para a socialização do conhecimento, já que viabiliza a autonomia dos trabalhadores e o uso das habilidades aprendidas no contexto do trabalho. (Von Krog, Ichijo \& Nonaka, 2001). Portanto, a organização, segundo Nonaka \& Takeuchi (2004), poderá alcançar êxito na sua função social, pois busca estar baseada nas competências, na criatividade e nas atividades agregativas de valor dos trabalhadores do conhecimento, criando-se assim, em nível organizacional, suas core competências que poderão diferenciá-las no mercado.

Tabela 2. Resultado das ocorrências percentuais dos indicadores do componente Suporte Organizacional 


\begin{tabular}{|l|c|c|c|c|c|}
\hline \multirow{2}{*}{\multicolumn{1}{|c|}{ Indicadores }} & \multicolumn{5}{c|}{ OCORRENCIAS EM PERCENTUAL } \\
\cline { 2 - 6 } & Nunca & Ocasionalmente & $\begin{array}{c}\text { Com alguma } \\
\text { frequência }\end{array}$ & Muitas Vezes & Sempre \\
\hline Chefia Imediata & $0,00 \%$ & $7,56 \%$ & $17,65 \%$ & $36,97 \%$ & $37,82 \%$ \\
\hline $\begin{array}{l}\text { Recursos Materiais / } \\
\text { Equipamentos e Ferramentas }\end{array}$ & $0,00 \%$ & $0,00 \%$ & $13,24 \%$ & $39,71 \%$ & $45,59 \%$ \\
\hline Relações Sociais no Trabalho & $0,00 \%$ & $0,00 \%$ & $17,65 \%$ & $20,59 \%$ & $61,76 \%$ \\
\hline Socialização do Conhecimento & $0,00 \%$ & $3,92 \%$ & $15,69 \%$ & $32,35 \%$ & $48,04 \%$ \\
\hline
\end{tabular}

Fonte: dados da pesquisa.

Quanto ao indicador "Recursos Materiais / Equipamentos e Ferramentas", tem-se que 'sempre' ou 'muitas vezes' na percepção dos servidores a organização tem viabilizado/ disponibilizado os recursos materiais, móveis, equipamentos, ferramentas e similares em quantidade e qualidade necessários ao bom uso das habilidades aprendidas no treinamento para o trabalho. Segundo Brito (2005); Davenport \& Prusak (1998), esses recursos/ferramentas se revestem de importância, pois são meios que podem ser utilizados para disseminação do conhecimento explícito adquirido através da educação. Autores como Tasca et al. (2011); Medeiros \& Levy (2010); Borges-Andrade et al. (2009); Von Krogh et al. (2001), ainda colocam que o suporte organizacional corrobora para melhorar processos, facilita o uso de novas tecnologias e, sobretudo criar ambientes que favoreçam a inovação.

O indicador "Relações Sociais no Trabalho", revelou que 'sempre' os colegas ou grupos de trabalho buscam a interação e dão orientações uns aos outros quando persiste alguma dificuldade na aplicação das novas habilidades aprendidas no treinamento para o trabalho. Ratifica o colocado por Davenport \& Prusak (1998) que é na interação entre os trabalhadores, ou seja, através das habilidades das pessoas (inteligência, sensibilidade, discernimento, criatividade e capacidade de inovação), que ele - o conhecimento é disseminado provocando-se a aprendizagem organizacional, pois o conhecimento se aperfeiçoa com o uso.

Referente ao indicador "Socialização do Conhecimento", demonstrou-se que 'sempre' ou 'muitas vezes' os trabalhadores do conhecimento, entre eles os mais experientes, recebem e são estimulados pela organização a prestar as informações necessárias que são levadas em consideração para a correta aplicação das habilidades aprendidas no trabalho. Além disso, os grupos de trabalho são incentivados a aprender com as experiências bem-sucedidas de outros setores da instituição. Significa que na percepção de Drucker \& Howard (2000), por exemplo, a organização viabiliza trabalhadores capazes de analisar dados transformando-os em informação e buscar o significado da informação transformando-a em conhecimento com relevância e propósito - o ativo intangível mais importante da atual realidade e disseminá-lo para os demais para que todos possam resolver os problemas do dia a dia.

\subsection{Impacto do treinamento}

A avaliação de Impacto do treinamento, conforme a Tabela 3, demonstra que em nível do indivíduo, na percepção dos gestores Técnico-Administrativos em Educação ocupantes de Função Gratificada e/ou de Cargo de Direção, 'muitas vezes' o treinamento trouxe impacto, ou seja, propiciou melhor competência aos trabalhadores para execução das tarefas do dia a dia. Significa dizer que, de acordo com Borges-Andrade et al. (2009); Abbad et al. (2003), melhorou o desempenho individual dos trabalhadores no trabalho através da mudança, ou seja, de uma nova forma de desempenhar antigas tarefas a partir dos novos $\mathrm{CHAs}$ adquiridos. 
Tabela 3. Resultado geral das ocorrências percentuais do componente Impacto

\begin{tabular}{|l|c|c|c|c|c|}
\hline \multirow{2}{*}{ Componente } & \multicolumn{5}{|c|}{ OCORRÊNCIAS EM PERCENTUAL } \\
\cline { 2 - 6 } & Nunca & Ocasionalmente & $\begin{array}{c}\text { Com alguma } \\
\text { frequência }\end{array}$ & Muitas Vezes & Sempre \\
\hline Impacto do treinamento & $2,45 \%$ & $7,84 \%$ & $22,06 \%$ & $42,16 \%$ & $25,49 \%$ \\
\hline
\end{tabular}

Em seguida tem-se a distribuição dos Indicadores do componente Impacto, utilizados para o aprofundamento da análise dos dados.

\subsection{Indicadores de impacto do treinamento}

A partir dos indicadores do componente Impacto, conforme a Tabela 4, percebeu-se quanto a "Qualidade e Eficiência no Trabalho" que em 'muitas vezes' os CHAs aprendidos no treinamento possibilitaram que os trabalhadores cometessem menos erros e executassem com mais rapidez as mesmas atividades, mesmo aquelas que pareciam não estar relacionadas diretamente com o conteúdo do treinamento. Conforme Sveiby (1998), significa que os trabalhadores podem ter desenvolvido a capacidade de agir em diversas situação e isso pode estar relacionado diretamente com a participação no treinamento, pois conforme Brito (2005); Tavares (2010) a competência está relacionada com a escolaridade, a capacidade de solucionar as incertezas do dia-a-dia através da arte de "saber fazer" que envolve a proficiência prática física e mental - experiência, visto que esta será a base para a construção de novos conhecimentos.

Tabela 4. Resultado das ocorrências percentuais dos indicadores do componente Impacto

\begin{tabular}{|l|c|c|c|c|c|}
\hline \multirow{2}{*}{\multicolumn{1}{c|}{ Indicador }} & \multicolumn{5}{c|}{ OCORRÊNCIAS EM PERCENTUAL } \\
\cline { 2 - 6 } & Nunca & Ocasionalmente & $\begin{array}{c}\text { Com alguma } \\
\text { frequência }\end{array}$ & $\begin{array}{c}\text { Muitas } \\
\text { Vezes }\end{array}$ & Sempre \\
\hline Qualidade e Eficiência no trabalho & $1,47 \%$ & $11,76 \%$ & $14,71 \%$ & $48,53 \%$ & $23,53 \%$ \\
\hline Motivação para o trabalho & $2,94 \%$ & $5,88 \%$ & $25,74 \%$ & $38,97 \%$ & $26,47 \%$ \\
\hline
\end{tabular}

Fonte: dados da pesquisa

Quanto ao indicador "Motivação para o Trabalho", demonstrou-se que por 'muitas vezes' a participação dos trabalhadores no treinamento serviu para aumentar sua motivação e autoconfiança na execução das novas habilidades e socialização do conhecimento no trabalho. Os trabalhadores colocam em prática o que foi aprendido, sugerem com mais frequência e estão mais receptivos às mudanças nas rotinas de trabalho. Isso demonstra, conforme Davenport e Prusak (1997), a aquisição de competências pelos trabalhadores, tanto em nível das competências hard (conhecimento estruturado, qualificações técnicas e experiência profissional) e de atributos soft (um claro senso dos aspectos culturais, políticos e pessoais do conhecimento).

\subsection{Análise do suporte e do impacto do treinamento}

Portanto, a partir dos componentes do modelo proposto pelos autores Borges-Andrade et al. (2009), com o aprofundamento da análise a partir da categorização das perguntas do questionário em indicadores e com base na teoria sobre o assunto, se percebeu que:

a) as chefias imediatas prestam suporte e criam oportunidades para planejar o uso das novas habilidades adquiridas pelos trabalhadores, e isso tem viabilizado a utilização com 
frequência das novas competências, habilidades e atitudes que trazem impacto na resolução dos problemas do dia a dia da organização;

b) o treinamento teve impacto, pois, quando os trabalhadores do conhecimento aplicam as novas habilidades aprendidas erram menos, com isso recebem elogios das chefias imediatas como forma de suporte;

c) houve suporte ao treinamento, pois, os trabalhadores são encorajados pelas chefias imediatas a aplicar o que aprenderam no treinamento, encontram as informações necessárias e as ferramentas e materiais necessários para a aplicação das novas habilidades no trabalho. Além disso, as chefias imediatas tem criado oportunidades para o trabalho em equipe propiciando a interação entre os trabalhadores e a socialização do conhecimento, principalmente a partir dos mais experientes e das experiências exitosas dos outros setores, e incentivam e dão autonomia para que os trabalhadores apliquem o que aprenderam através da mudança das rotinas de trabalho, as chefias também assumem com os trabalhadores os riscos de tentar novas formas de realizar o trabalho, e com alguma frequência o treinamento beneficiou os colegas / grupo de trabalho, pois puderam aprender uns com os outros, já que houve estímulo à interação entre as pessoas para que aprendam.

d) na organização existem pessoas mais experientes estimuladas que prestam suporte aos demais trabalhadores para repassar seus conhecimentos quando algum deles tem dificuldades na sua aplicação;

e) o treinamento teve impacto, pois, após o treinamento os trabalhadores tem sugerido com mais frequência e as sugestões tem sido aceitas ou levadas em consideração pelas chefias imediatas. Além disso, com alguma frequência os trabalhadores tem sugerido mudanças nas rotinas e estas são levadas em consideração.

\section{CONCLUSÕES}

Os resultados da pesquisa corroboram com a tendência apresentada na literatura da área de Gestão de Pessoas, Gestão por Competências e Gestão do Conhecimento, e demonstram que no campus da instituição de educação, ciência e tecnologia pesquisado, também cresceu a importância pelo conhecimento tanto em nível individual, quanto no nível organizacional, pois considerando-se o objetivo da pesquisa, tem-se de modo geral uma avaliação satisfatória por parte dos servidores respondentes quanto ao suporte do treinamento recebido, pois $75 \%$ deles avaliaram que 'sempre' ou 'muitas vezes' tiveram suporte organizacional para transferência e utilização do conhecimento e das habilidades aprendidas; enquanto, na percepção dos gestores o treinamento tornou os trabalhadores, e consequentemente a organização mais competentes para a resolução dos problemas.

Significa dizer que para as pessoas o conhecimento aprendido no treinamento poderá torná-las "competente" devido a proficiência no "saber fazer" e a capacidade de resolver os problemas do dia a dia causando-se impacto na sociedade. Para a organização pode ser a tentativa de estabelecer uma cultura de criação e disseminação do conhecimento que poderá projetá-la para o futuro e torná-la competitiva na área do conhecimento em que atua, pois a instituição pode estar preocupada em aperfeiçoar seu fazer institucional, manter a qualidade e eficiência administrativa, e consolidar através do suporte organizacional bases mais consistentes de conhecimento que podem proporcionar a construção de relacionamentos e confiança mútua entre os servidores e para com a região, agregar valor público aos serviços que oferece, 
estabelecer consenso pela educação, educar os trabalhadores para a flexibilidade e os novos modelos de gestão, motivá-los, propiciar condições facilitadoras para a aprendizagem e disseminação do conhecimento.

Isso poderá possibilitar, ainda, à instituição pesquisada lidar com as pressões legítimas de uma sociedade cada vez mais exigente, reduzir a fragmentação e falta de coordenação de ações, superar isolamentos e contar com servidores capazes de estabelecer parcerias e convênios; criar valor público: produzir serviços, resultados e criar confiança da população com relação às ações; e preparar pessoas para saber agir através de hábitos, valores e comportamentos adequados ao exercício de sua função, para atender a demandas sempre crescentes e sem recursos suficientes (humanos, tecnológicos e orçamentários).

Conclui-se, portanto, que todas as variáveis da pesquisa, sejam do componente Suporte Organizacional ou do Impacto, concorreram para a avaliação positiva do treinamento, pois a partir do processo de aquisição e aplicação dos novos conhecimentos, habilidades e atitudes no trabalho houve a qualificação da ação institucional (suporte organizacional) através da qualidade e eficiência dos trabalhos realizados pelos trabalhadores do conhecimento (impacto). Destarte, pode-se entender que se cumpre o objetivo das organizações contemporâneas, ou seja, viabilizar a conversão do conhecimento tácito dos trabalhadores em conhecimento explícito de modo que seja disseminado amplamente para que gere valor em produtos e serviços, na tomada de decisão, gere inovação, novos processos e diferencie a organização no mercado.

Como limitações do estudo, tem-se que os dados foram recolhidos a partir de apenas uma amostra no Nordeste do Brasil e, portanto, suas descobertas não podem ser inferidas em outros contextos. A pesquisa ainda tem limitações quanto a triangulação dos dados, sendo necessário o retorno dos pesquisadores aos pesquisados para se perceber, a partir da subjetividade constituída na atividade dos TAEs treinados, qual o real impacto do treinamento no serviço que é entregue para a sociedade.

As sugestões de trabalhos futuros residem em estudos empíricos com a utilização do método quantitativo ou estudos comparativos, e estudos longitudinais para superar as limitações de um método único.

\section{REFERÊNCIAS}

Abbad, G., Pilati, R., \& Pantoja, M. J. (2003). Avaliação de treinamento: análise da literatura e agenda de pesquisa. Revista de Administração da Universidade de São Paulo, 38(3), 205-218.

Abranches, S. (2017). A era do imprevisto. A grande transição do século XXI. São Paulo: Companhia das Letras.

Alves, A. R., \& Tamayo, Á. (1993). Sistema de avaliação do treinamento da Telebrás SAT. Revista de Administração da Universidade de São Paulo, 28(4), 73-80.

Bastos, A. (1994). Comprometimento no trabalho: a estrutura dos vínculos do trabalhador com a organização, a carreira e o sindicato. Universidade de Brasília. Brasília (Doctoral dissertation, Tese).

Borges-Andrade, J. E., Abbad, G. da S., \& Mourão, L. (2009). Treinamento, desenvolvimento e educação em organizações e trabalho. Artmed Editora. 
Brasil. (2006). Decreto no 5.707/2006. Recuperado em 01 julho, 2015, de http://www.planalto.gov.br/CCIVIL_03/_Ato2004-2006/2006/Decreto/D5707.htm.

Brito, L. M. P., Oliveira, P. W. S. de, \& Castro, A. B. C. de. (2012). Gestão do conhecimento numa instituição pública de assistência técnica e extensão rural do Nordeste do Brasil. Revista de Administração Pública-RAP, 46(5). DOI: 10.1590/S0034-76122012000500008.

Brito, L. M. P. (2008). Prática de pesquisas em gestão de pessoas 2: a tênue separação entre o público e o privado no Brasil. Fortaleza: Edições UFC.

Brito, L M. P. (2005). Gestão de competências, gestão do conhecimento e organizações de aprendizagem: instrumentos de apropriação pelo capital do saber do trabalhador. Fortaleza: Imprensa Universitária.

Bukowitz, W. R., \& Williams, R. L. (2002). Manual de gestão do conhecimento: ferramentas e técnicas que criam valor para a empresa. Bookman.

Castro, A. B. C. de, Brito, L. M. P., \& Varela, J. D. S. (2017). A ressignificação da área de gestão de pessoas e os novos papéis das pessoas e das organizações. HOLOS, 33(4), 408-423. DOI: 10.15628/holos.2017.5168.

Cogpe. (2011). Projeto de estruturação da gestão de pessoas. Relatório de Gestão de Pessoas, Apodi, Brasil.

Drucker, P. F., \& Howard, R. (2000). Aprendizado organizacional: gestão de pessoas para a inovação contínua. Rio de Janeiro: Campus.

França, A. C. L. (2008). Práticas de recursos humanos: conceitos, ferramentas e procedimentos. Revista de Administração Contemporânea, 12(2), 583-583.

Godoy, A. S. (1995). Introdução à pesquisa qualitativa e suas possibilidades. Revista de administração de empresas, 35(2), 57-63.

Política de capacitação. (2013). Resolução no 20/2005-CD. Recuperado em 01 julho, 2015, de http://portal.ifrn.edu.br/servidores/politica-de-capacitacao.

Prusak, L., \& Davenport, T. (1998). Conhecimento empresarial: como as organizações gerenciam o seu capital intelectual. Rio de Janeiro: Elsevier.

Lingham, T., Richley, B., \& Rezania, D. (2006). An evaluation system for training programs: a case study using a four-phase approach. Career development international, 11(4), 334-351. DOI: 10.1108/13620430610672540.

Medeiros, P. C., \& Levy, E. (2010). Construindo uma nova gestão pública. Natal: SEARH/RN.

Meister, J. C., \& Willyerd, K. (2013). O ambiente de trabalho de 2020. Como as empresas inovadoras atraem, desenvolvem e mantém os funcionários do futuro nos dias de hoje. Rio de Janeiro: Alta Books. 
Meister, J. (1999). Educação corporativa: a gestão do capital intelectual através das universidades corporativas. São Paulo: Makron Books.

Merriam, S. B. (1998). Case study research in education: A qualitative approach. Jossey-Bass.

Nonaka, I., \& Takeuchi, H. (2004). Criação de conhecimento na empresa. Elsevier Brasil.

Roggero, R. (2018). Qualificação e competência: um diálogo necessário entre sociologia, gestão e educação para alimentar as práticas pedagógicas na formação profissional. Boletim Técnico do SENAC, 29(3), 16-29.

Senge, P. R. (2012). A quinta Disciplina: arte e prática da organização que Aprende. São Paulo: Best Seller.

Senge, P. (1999). A dança das mudanças: os desafios de manter o crescimento eo sucesso em organizações que aprendem. Campus. Rio de Janeiro: Campus.

Stewart, T. A. (1998). Capital intelectual: a nova vantagem competitiva das empresas (Vol. 2). Rio de Janeiro: Campus.

Sveiby, K. E. (2003). A nova riqueza das organizações: gerenciando e avaliando patrimônios de conhecimento. Rio de Janeiro: Campus.

Tasca, J. E., Ensslin, L., \& Ensslin, S. R. (2012). A avaliação de programas de capacitação: um estudo de caso na administração pública. Revista de Administração Pública-RAP, 46(3).

Tavares, W. R. (2010). Gestão do conhecimento: Educação e Sociedade do Conhecimento. São Paulo: Ícone.

Von Krogh, G., Ichijo, K., \& Nonaka, I. (2001). Facilitando a criação de conhecimento: reinventando a empresa com o poder da inovação contínua. Rio de Janeiro: Campus.

Yin, R. K. (2015). Estudo de Caso: Planejamento e Métodos. Porto Alegre: Bookman editora. 